\title{
O processo de implantação dos assentamentos rurais em Santana do Livramento (RS)
}

\author{
The process of implementation of rural settlements in Santana do Livramento (RS) \\ Jeferson da Luz Ferron', Alessandra Troian"
}

\begin{abstract}
Resumo:
As características históricas de formação econômica do Brasil, calcada em cima da grande propriedade e da monocultura para exportação, marca os conflitos de interesse e de poder em torno da posse e acesso à terral. No entanto, nas últimas décadas tem-se assistido a pressão dos movimentos sociais e a luta pelo acesso à terra. Neste sentido, o presente estudo visa apresentar o estabelecimento dos assentamentos rurais em Santana do Livramento (RS). Metodologicamente a pesquisa caracteriza-se como qualitativa, realizada a partir da análise documental e bibliográfica. Como resultados destaca-se que o estabelecimento dos assentamentos rurais em Santana do Livramento ocorreu em concomitância ao processo de fortalecimentos das políticas em reforma agrária no Brasil. A partir da década de 1990, com a criação de 15 assentamentos o município passou a fazer parte do mapa da reforma agrária brasileira, sem resistência por parte dos fazendeiros locais. Contudo, nos anos 2000, período em que houve o desenvolvimento de mais 15 assentamentos, houve discordância com a vinda dos agricultores assentados resultando em conflitos públicos, protagonizados por pecuaristas tradicionais do município, entes públicos e demais atores sociais. Atualmente Santana do Livramento conta com 30 assentamentos rurais, os quais dão dinâmica social e econômica à região.
\end{abstract}

Palavras-chave: Reforma agrária; Políticas públicas; Desenvolvimento local

\begin{abstract}
:
The historical characteristics of Brazil's economic formation, based on large property and monoculture for export, mark the conflicts of interest and power surrounding land ownership and access. However, in recent decades there has been pressure from social movements and the struggle for access to land. In this sense, the present study aims to present the establishment of rural settlements in Santana do Livramento (RS). Methodologically the research is characterized as qualitative, carried out from the documentary and bibliographical analysis. As a result, it is noteworthy that the establishment of rural settlements in Santana do Livramento occurred concurrently with the process of strengthening the policies on agrarian reform in Brazil. From the 1990s, with the creation of 15 settlements, the municipality became part of the map of Brazilian agrarian reform, without resistance from local farmers. However, in the 2000s, when 15 more settlements were developed, there was disagreement with the arrival of settled farmers resulting in public conflicts, led by traditional farmers of the municipality, public entities and other social actors. Santana do Livramento currently has 30 rural settlements, which give the region social and economic dynamics.
\end{abstract}

Keywords: Land reform; Public policy; Local development

IMestre em Administração pela Universidade Federal do Pampa - jefersonferron@unipampa.edu.br

I"Doutora em Desenvolvimento Rural (UFRGS) - alessandratroian@unipampa.edu.br 


\section{Introdução}

O processo de redemocratização observado no final da década de 1980 no Brasil foi acompanhado do fortalecimento dos movimentos sociais, principalmente no meio rural. Segundo Miranda e Fiúza (2017), os problemas vivenciados pelos trabalhadores assalariados, camponeses e suas famílias estavam sobremaneira vinculados à exploração e à marginalização inerente da modernização agrícola, os quais endossavam as mobilizações no campo. Por essa razão, dentre as principais pautas de reivindicações dos movimentos sociais rurais, estavam o acesso a terra e aos direitos sociais.

Conforme ressalta Mocelin (2018, p. 84), os movimentos sociais rurais que emergem e se expressam na década de 1980 são arena de dupla resistência política: ora porque estavam posicionados contra a ordem social excludente; ora porque estavam contra as organizações formais de representação social. Apoiados pela igreja católica e por partidos políticos de esquerda, passaram a realizar importantes ações em pressão ao Governo Federal, para que as grandes propriedades rurais fossem fiscalizadas e para que propriedades consideradas improdutivas fossem desapropriadas e transformadas em assentamentos rurais, possibilitando o seu acesso por diversas famílias de agricultores em situação de vulnerabilidade socioeconômica (MEDEIROS, 2003; FILIPPI, 2005; SCHNEIDER, 2009).

Uma parte expressiva desses assentamentos foi implantada no município gaúcho de Santana do Livramento, marcado historicamente pela presença do latifúndio e que teve durante muito tempo a pecuária como sua principal atividade econômica, suprindo por décadas diversos frigoríficos da região (ALBORNOZ, 2000; CAGGIANI, 1983). Contudo, a partir da década de 1990, visualiza-se no espaço agrário do município constante processo de mudanças importantes, advindas da instalação de assentamentos rurais vinculados ao Instituto Nacional de Colonização e Reforma Agrária (INCRA) (CHELOTTI, 2003; AGUIAR, 2011; FERRON, TROIAN, ALBUQUERQUE, 2019).

Sendo assim, Santana do Livramento insere-se no mapa da reforma agrária brasileira no ano de 1992, oportunidade em que ocorre a implementação do seu primeiro assentamento rural. A partir disso, a cidade símbolo da integração do MERCOSUL (Lei 12.095/2009), caracterizada historicamente pela produção agropecuária, implementou 30 assentamentos rurais do Instituto Nacional de Colonização e Reforma Agrária, que juntos possuem uma área de 26.528 hectares e abrigam aproximadamente 907 famílias. Essa realidade faz de Santana do Livramento o município com maior número de assentamentos no Rio Grande do Sul (INCRA, 2017).

A inclusão dos assentamentos rurais representou mudanças e transformações no pampa gaúcho, contrastando com as grandes propriedades rurais, como destacado por Chelotti (2003), Aguiar (2011) e Monteblanco (2013). Famílias vindas de diversas regiões do Estado introduziram novas formas de organização no campo, produção, cultivo e relações socioeconômicas diversificadas (AGUIAR, 2011).

De acordo com o INCRA (2019), cada família assentada recebeu em média vinte e cinco hectares. Embora a área total destinada aos assentamentos no município seja menor que 5\% do território municipal e o acesso ainda seja precário em diversas localidades - em virtude das más condições de conservação das estradas (MONTEBLANCO, 2013) -, essas famílias têm conseguido se reproduzir socialmente e transformar o espaço rural em algo "novo", como preconizado por Graziano da Silva (1999).

Entretanto, o processo de implantação dos assentamentos rurais foi complexo e marcado por embates político-sociais. Sendo assim, a análise do processo de desenvolvimento dos assentamentos rurais no referido município torna-se relevante. O presente estudo, sob a perspectiva da análise documental e bibliográfica, discorre sobre o estabelecimento dos assentamentos rurais em Santana do Livramento (RS)1.

O texto está organizado em cinco seções, a incluir essa breve introdução. Em sequência, discorre-se sobre a questão agrária no Brasil, abordando desde o processo de ocupação da terra no Brasil colônia às disputas recentes, pós redemocratização. Por conseguinte, apresenta-se um breve histórico do processo de reforma agrária no Brasil. Ainda se aborda acerca da formação econômica no Rio Grande do Sul, destacando o processo de implantação de assentamentos rurais em Santana do Livramento. Por fim, ilustram-se as considerações finais do estudo, bem como as referências consultadas durante a elaboração do texto.

\section{A questão agrária no Brasil: da ocupação do território às disputas políticas e pela terra}

Segundo Furtado (2007), o problema da concentração fundiária no Brasil remonta ao início da colonização, cujo sistema de concessão de terras prevaleceu apenas para quem dispusesse de meios para explorá-las, tendo na exportação da produção excedente para a Coroa Portuguesa o seu objetivo principal. O início do processo exploratório se deu em 1534 com a criação das capitanias hereditárias por D. João III - rei de Portugal.

1 O artigo é um recorte da pesquisa de mestrado do primeiro autor, que resultou na dissertação de mestrado intitulada "Estratégias de reprodução social dos agricultores familiares assentados em Santana do Livramento/RS”, defendida em março de 2019 no Programa de Pós-Graduação em Administração da Universidade Federal do Pampa (PPGA/Unipampa), campus Santana do Livramento/RS. 
De acordo com Santos (2014), a criação das capitanias hereditárias não se deu de forma pacífica, uma vez que, a exemplo do que ocorrera com os Maias e Astecas no México e com os Incas a Oeste da América do Sul, os índios brasileiros reagiram e foram brutalmente assassinados e/ou escravizados. Entre as principais obrigações dos donatários, membros da nobreza portuguesa que eram agraciados com as terras, estavam a criação de vilarejos e a doação de sesmarias para cristãos que possuíssem condições financeiras para explorá-las (FURTADO, 2007; VERAS NETO, 2013).

O sistema de sesmarias teve início com a expedição de Martim Afonso de Souza para o Brasil no início da década de 1530 e continuou em vigência até 17 de julho de 1822 (SANTOS, 2014). Após o fim do sistema, durante 28 anos o Brasil permaneceu sem qualquer lei que regulamentasse a aquisição de terras. As terras devolutas passaram a ser povoadas de maneira descontrolada por homens livres, que tinham a intenção de ocupá-las e torná-las produtivas. Esse tipo de ocupação teve fim em 1850, com a criação da Lei no 601, que ficou conhecida como Lei de Terras (VERAS NETO, 2013). O período imperial brasileiro foi marcado pela total ausência de democratização do acesso à terra, uma vez que a Constituição de 1824 concedeu a propriedade das terras devolutas do país ao Governo Imperial (SANTOS, 2014; BACHA, 2012).

A base da economia brasileira, na época da colônia, foi construída através de latifúndios, que tinham na monocultura sua única forma de subsistência. A abundância de terras tornava impraticável a utilização de mão de obra assalariada (VERAS NETO, 2013; BACHA, 2012). Foi nesse período que iniciou o tráfico de escravos oriundos da África. Em grande parte, o pensamento escravocrata baseava-se na supremacia da raça branca, entendendo que as raças inferiores deveriam ser obrigadas e forçadas ao trabalho, pois eram preguiçosas e acomodadas (VERAS NETO, 2013). Origina-se desse processo também, considerável parcela dos problemas de concentração demográfica brasileira e acesso digno a moradia, conforme observado pelo autor:

Estes processos de concentração fundiária no passado, com a abolição da escravatura sem distribuição de terra para os libertos, contribuíram por descartar historicamente, a massa africana alforriada, que troca as senzalas pelas favelas. Essa parcela da população fica excluída das áreas urbanas constituindo bantustões dentro de um apartheid social com seus muros invisíveis. Isto esconde a vergonha da exclusão social do negro no Brasil, na qual é possível encontrar condomínios de luxo ao lado de favelas como parte da paisagem de cidades brasileiras como o Rio de Janeiro (VERAS NETO, 2013, p.36).

A partir de 1888, com o fim da escravidão, o Brasil perdeu a oportunidade de resolver dois problemas históricos: i) a reforma agrária, tendo em vista que as pessoas escravizadas foram trazidas para trabalhar em atividades agrícolas e, uma vez libertos, poderiam se tornar produtores rurais livres contribuindo para o povoamento e desenvolvimento de diversas regiões agrícolas; ii) ao crescimento populacional nas grandes cidades, uma vez que não restou outra opção aos alforriados de que se instalarem próximo aos grandes centros urbanos em busca de trabalho (VERAS NETO, 2013).

Sendo assim, a Lei de Terras de 1850 passou a regulamentar a compra e venda de terras no Brasil, restringindo a posse a uma minoria, tendo em vista que não poderiam ser proprietários de terra os ex-escravos, os imigrantes, os posseiros e os brasileiros pobres. A esses segmentos não restou alternativa, qual seja, colocar sua força de trabalho a serviço dos grandes latifúndios, com mão de obra barata e abundante (SANTOS, 2014).

A Lei de Terras de 1850 legitimava o direito de posse em terras ocupadas efetivamente e recompensava o cultivo eficiente, cedendo aos posseiros outras partes de terra para quem dispusesse de meios para produzir. Assim, garantia-se o acesso de uma parcela (desde que não fossem imigrantes, ex-escravos e/ou brasileiros pobres) da sociedade brasileira à aquisição das terras (MEDEIROS, 2003).

Conforme Furtado (2007), é a Lei de Terras que passa a estabelecer a propriedade privada no Brasil, adquirindo importância comercial e maior valorização econômica. De acordo com Nakatani, Faleiros e Vargas (2012), as terras que não pertenciam a nenhum ocupante foram declaradas devolutas e pertencentes ao Estado, o qual foi conivente com falsificações de títulos, documentos e registros topográficos. Desta forma, é possível perceber que a lei pouco alterou a organização fundiária nacional e o poder político dos grandes proprietários de terra.

Na verdade, o objetivo dessa legislação era bloquear o acesso à terra por parte da população supostamente livre (dado o esgotamento da escravidão), antecipando o que poderia ser uma ameaça ao poder de parcela da elite nacional, qual seja, a quebra do monopólio da terra. Nestes termos, e ainda com Florestan Fernandes, bloqueiase a constituição de uma ordem social competitiva e bloqueiase violentamente o processo de mobilidade social, como que congelando o tempo histórico e político, e, nesse bojo, a questão agrária (NAKATANI; FALEIROS; VARGAS, 2012, p. 19).

Após a Proclamação da República, verifica-se que a Constituição de 1891 em nada alterou a Lei de Terras, ao contrário do Código Civil de 1916, que além de legalizar o arrendamento e a locação de serviços, tornou possível a realização de parcerias no campo, incentivando e fornecendo condições legais para o fortalecimento de grandes 
propriedades rurais (BACHA, 2012). Conforme Pereira (2013), a partir do Código Civil de 1916 com o fortalecimento das grandes propriedades rurais, observam-se as primeiras reinvindicações dos agricultores sem terras frente ao quadro de exclusão que foram expostos, uma vez que continuar trabalhando no latifúndio era uma das únicas formas possíveis de subsistência desses trabalhadores. Ainda conforme o autor, a ameaça da quebra do vínculo do trabalhador com a grande propriedade rural, mediante a expulsão do agricultor camponês da terra onde trabalhava, constituía-se por si só em uma oportunidade de resistência (FERRON, TROIAN, ALBUQUERQUE, 2019).

Nesse sentido, Medeiros (2003) destaca que um dos primeiros grupos a questionar publicamente a organização fundiária brasileira foi o Movimento Tenentista de 1920. Conforme a autora, a existência do latifúndio estava diretamente relacionada ao coronelismo e ao controle político dos eleitores pelos grandes proprietários de terras.

Todavia, os questionamentos em torno da questão agrária brasileira, no início do século passado, não foram levantados exclusivamente pelo movimento tenentista de 1920. Conforme Filippi (2005, p. 45), a criação da Sociedade Rural Brasileira em 1919, entidade que defende a propriedade da terra e se opõe a quaisquer políticas de reforma agrária até os dias atuais, surgiu com o intuito de "promover o desenvolvimento socioeconômico do país com base no avanço competitivo da produção primária rural e do sistema agroindustrial”.

Outra organização que historicamente mantém interesse na questão agrária brasileira é a igreja católica, cuja preocupação voltava-se para o aspecto social do campo. Os principais objetivos da igreja eram manter a unidade de trabalho familiar rural, contendo assim os processos de êxodo rural e, principalmente, evitar que os trabalhadores rurais tivessem contato com as ideias comunistas, em franca expansão nos centros urbanos (PEREIRA, 2013). De acordo com Martins (1995), para a igreja católica, apenas a fixação do trabalhador à terra seria capaz de conter o êxodo e a proletarização reivindicatória. Do mesmo modo, a única saída para salvar o trabalhador do comunismo seria transformando-o em pequeno proprietário. Cabe ressaltar o momento político mundial, pós revolução Russa de 1917, que possibilitou um novo modelo econômico em diversos países, interferindo sobremaneira nas reivindicações de trabalhadores urbanos e rurais de países que não implantaram o modelo

Verifica-se nesse período pós-Segunda Guerra Mundial a transferência de capitais das atividades agrícolas para as atividades industriais urbanas, originando, por conseguinte, um dos processos de migração mais violentos do século $\mathrm{XX}^{2}$. Essas mudanças originaram grande parte dos graves problemas urbanos verificados atualmente nas grandes cidades brasileiras (grande concentração populacional, ausência de moradia digna, desemprego, violência, entre outros), uma vez que populações inteiras de trabalhadores saíram do campo e foram para a cidade, sem trabalho, educação ou moradia (NAKATANI; FALEIROS; VARGAS, 2012).

Foi a partir do processo de industrialização brasileira que a questão fundiária ganhou espaço e começou a ser debatida pela sociedade, tendo em vista que, devido ao êxodo rural, houve uma rápida urbanização do país. Nesse

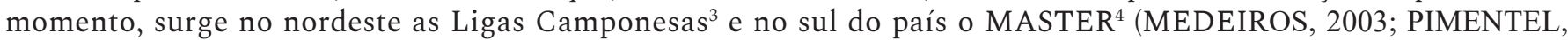
2004; FILIPPI, 2005).

Delgado (2001) destaca que, entre anos 1950 e 1960, a reflexão econômica sobre o meio rural brasileiro organizou-se em dois eixos temáticos: a "questão agrária” e "a industrialização e o papel da agricultura”. Conforme o autor, a construção teórica e política da "questão agrária” no pensamento econômico ocorreu de maneira mais intensa nos anos 1960, com contribuição fundamental de três eixos de reflexão da intelectualidade mais à esquerda, a saber: o Partido Comunista Brasileiro (PCB); setores progressistas da igreja católica e a Comissão Econômica para América Latina e o Caribe (CEPAL).

Delgado (2005) destaca três intelectuais agrários ligados ao Partido Comunista Brasileiro - Caio Prado Jr, Ignácio Rangel e Alberto Passos Guimarães - que protagonizaram, no campo marxista, a discussão teórica e política sobre a questão agrária nos anos 1960. De acordo com o autor, Caio Prado Jr. se preocupava com as condições sub-humanas de vida de grande parte da população rural brasileira. Já Alberto Passos Guimarães visualizava o latifúndio como uma forma de feudalismo agrário, cuja transformação não caberia ao capitalismo, mas sim à reforma agrária. Neste contexto, Ignácio Rangel destaca-se como o economista cuja preocupação volta-se para a superpopulação rural e os problemas decorrentes desse processo.

Como contraponto a essa corrente, emergiu um grupo de economistas da Universidade de São Paulo (USP), li-

2 A distribuição de terras em países como Rússia e Japão antecedeu o processo de industrialização e forneceu a base para o desenvolvimento, ao contrário do que ocorreu no Brasil, onde os regimes ditatoriais do século XX ignoraram a etapa de reorganização fundiária e apostaram no desenvolvimento nacional baseado no processo de industrialização. Dentre as consequências do modelo desenvolvimento econômico adotado no país, cita-se o êxodo rural, que contribuiu para o aumento considerável da população nas cidades e para o consequente aumento dos níveis de desemprego (PIMENTEL, 2004; SCHNEIDER, 2009).

3 Foram a expressão política de conflitos no nordeste Brasileiro, tendo origem em 1955, tendo como principais líderes o Deputado Estadual Francisco Julião. Receberam destaque nacional devido a sucessivas mobilizações, incluindo a pauta dos trabalhadores do campo em marchas nas ruas e nas cidades (MEDEIROS, 2003).

4 Movimento dos Agricultores Sem-Terra. Criado, mais especificamente no Rio Grande do Sul. A composição do movimento era semelhante ao público das ligas camponesas: trabalhadores rurais, parceiros e agricultores familiares (FILIPPI, 2005). 
derados por Delfim Neto que com base em argumentos estatísticos, revelaria a inconsistência da "questão agrária" (DELGADO, 2001).

Delfim Neto e toda uma geração de economistas e econometristas da USP, demonstram a tese da resposta funcional da oferta agrícola às pressões da demanda, tentando desta forma desmontar o argumento implícito da rigidez da oferta agrícola, qual seja a inadequação da estrutura agrária. Esta, ao não permitir que a agricultura respondesse às pressões da demanda, provocaria tensões inflacionárias e crises recorrentes de abastecimento (DELGADO, 2001, p. 4).

O debate agrário proposto por Delfim Neto centrava no papel da agricultura para o desenvolvimento econômico, em que a proposta da reforma agrária seria totalmente dispensável. A tese da "modernização sem reforma" foi o caminho escolhido pelo golpe militar de 1964 e acabou com a efervescência do debate agrário daquele momento, utilizando para isso o "argumento" da força (DELGADO, 2001; 2005).

Neste sentido, Graziano da Silva (1981) infere que a modernização da agricultura brasileira, observada a partir da década de 1960, foi financiada pelo Estado e ocorreu de maneira conservadora, uma vez que favoreceu os grandes produtores. Ao mesmo tempo, constituiu um processo doloroso, pois impulsionou as contradições sociais geradas pela expansão do capitalismo no campo, marginalizou parcela dos produtores que não conseguiram acompanhá-lo, proletarizou agricultores familiares e camponeses que antes viviam da terra, motivou o êxodo rural impactando diretamente no meio urbano e comprometeu parte da biodiversidade nacional.

De outra forma, a chamada modernização da agricultura, instalada no Brasil a partir da década de 1960, absorveu quantidades crescentes de crédito agrícola, incorporou os chamados "insumos modernos" ao seu processo produtivo, tornando técnica e mecânica a produção agrícola e integrou-se aos denominados modernos circuitos de comercialização. O aumento da produtividade tornou possível a elevação da produção de matérias-primas e alimentos para a exportação e mercado interno, dando origem ao chamado "complexo agroindustrial" ou "industrialização da agricultura" (PALMEIRA, 1989; PIMENTEL, 2004).

Essa modernização, que se fez sem que a estrutura da propriedade rural fosse alterada, teve, no dizer dos economistas, "efeitos perversos": a propriedade tornou-se mais concentrada, as disparidades de renda aumentaram, o êxodo rural acentuou-se, aumentou a taxa de exploração da força de trabalho nas atividades agrícolas, cresceu a taxa de auto-exploração nas propriedades menores, piorou a qualidade de vida da população trabalhadora do campo. Por isso, os autores gostam de usar a expressão “modernização conservadora” (PALMEIRA, 1989, p. 87).

Verifica-se que a inovação e a tecnologia no campo, implantadas a partir de 1960, agravaram o problema da concentração fundiária e desencadearam importantes manifestações camponesas reivindicando o acesso à terra. Como consequência, o Governo Federal criou em outubro de 1962 a Superintendência da Política Agrária (SUPRA), cujo objetivo principal era colaborar na formulação da política agrária do país. Para tanto, a SUPRA promoveria a desapropriação de terras por interesse social, pautada por uma justa distribuição da propriedade rural e a prestação de serviços de assistência técnica aos trabalhadores rurais (PIMENTEL, 2004).

Nesse sentido, Bergamasco (1997) destaca que os movimentos sociais rurais foram fortemente reprimidos no período anterior a 1964, sendo que a opção do governo militar foi a modernização da agricultura. Por conseguinte, passa-se a intensificar a utilização de insumos químicos e mecânicos, sem alteração na concentrada estrutura fundiária brasileira. Como resultados perversos da modernização da agricultura, a autora ressalta a formação de uma classe de trabalhadores assalariados rurais, desprovidos de poder de compra e marcados pela precariedade das condições de trabalho e exclusão social. A precarização das condições de vida e de trabalho de milhões de trabalhadores acabou resultando no fortalecimento da organização política dos trabalhadores rurais.

\section{O processo de reforma agrária no Brasil: breve histórico}

Com a implantação do Regime Militar cria-se o Estatuto da Terra, Lei 4.504 de 1964, que estabelecia a reforma agrária como um conjunto de medidas, cujo objetivo era promover a melhor distribuição da terra, alterando o regime de posse como forma de suprir os princípios de justiça social e aumento de produtividade do campo (GUERRERO; BERGAMASCO; ESQUERDO, 2016). Nesse período, foram criados o Instituto Brasileiro de Reforma Agrária (IBRA) e o Instituto Nacional de Desenvolvimento Agrário (INDA), que substitui a SUPRA (INCRA, 2019). O Estatuto da Terra foi resultado do clima de insatisfação que imperava no meio rural, originado pelo temor do governo e, principalmente, das elites no poder, ante o provável surgimento de uma revolução camponesa, que teria por base a revolução cubana de 1959 (GUERRERO; BERGAMASCO; ESQUERDO, 2016).

Contrário à forma como o Estado se posicionou na questão agrária, Prado Jr. (1979) fez crítica ao Regime Militar. 
O pesquisador enfatizou não haver no Brasil reforma agrária de fato, mas que pós-1964 houve uma distribuição de terras insuficiente para a solução dos problemas de milhares de camponeses pobres. Como causa da pobreza, o autor destaca a colonização brasileira, que consistiu na expansão da empresa agromercantil em solo nacional, definindo atividades produtivas rurais, as regiões geoeconômicas e os papéis dos proprietários da terra e dos trabalhadores rurais.

Embora em 4 de novembro de 1966 tenha sido instituído o primeiro Plano Nacional de Reforma Agrária, por meio do Decreto n 59.456, esse não chegou a ser colocado em prática. Em julho de 1970, por meio do Decreto no 1.110, foi criado o Instituto Nacional de Colonização e Reforma Agrária (INCRA), que uniu o Instituto Brasileiro de Reforma Agrária e o Instituto Nacional de Desenvolvimento Agrário.

Durante a criação do INCRA, o Governo Brasileiro incentivou a colonização da Amazônia. Contingentes de migrantes de várias regiões brasileiras foram incentivados e convidados a habitar as margens da estrada Transamazônica. Além disso, organizações e empresas de diversos setores receberam incentivos fiscais para projetos agropecuários (PIMENTEL, 2004).

Com a conquista da democracia em 1984, mais uma vez o assunto reforma agrária vem à tona. O Decreto $\mathrm{n}^{\mathrm{o}}$ 97.766, de 10 de outubro de anos 1985, que instituiu o novo Plano Nacional de Reforma Agrária (PNRA) é resultado desse processo, cuja meta era oferecer 43 milhões de hectares para o assentamento de 1,4 milhão de famílias até 1989. Para tanto, o Governo Federal criou o Ministério Extraordinário para o Desenvolvimento e a Reforma Agrária (MIRAD). Passados quatro anos da criação do PNRA, a meta não havia sido atingida, uma vez que havia apenas 82.689 famílias assentadas no Brasil, em pouco mais de 4,2 milhões de hectares (MONTE, 2013).

Os resultados obtidos eram reflexo do debate político e ideológico em torno do tema reforma agrária na Assembleia Nacional Constituinte de 1987. Com o fortalecimento do debate, ocorre a extinção do INCRA em 1987 e do MIRAD em 1989. O Órgão responsável pela reforma agrária passou a ser o Ministério da Agricultura (OLIVEIRA, 2010).

A Constituição Federal de 1988 destacou a reforma agrária como um tema do capítulo da "Ordem econômica e social" e foi a primeira Lei Maior brasileira a abordar o tema. Em seu art. 5, inciso XXIII estabelece que a propriedade atenderá a função social (MEDEIROS, 2003) e, em seu Capítulo III sobre a política agrícola, fundiária e da reforma agrária, preconiza:

Art. 184. Compete à União desapropriar por interesse social, para fins de reforma agrária, o imóvel rural que não esteja cumprindo sua função social, mediante prévia e justa indenização em títulos da dívida agrária, com cláusula de preservação do valor real, resgatáveis no prazo de até vinte anos, a partir do segundo ano de sua emissão, e cuja utilização será definida em lei (CONSTITUIÇÃO DA REPÚBLICA FEDERATIVA DO BRASIL DE 1988).

Em março de 1989, por iniciativa do Congresso Nacional, o INCRA é recriado, porém a ausência de força política e a falta de recursos orçamentários fizeram com que a reforma agrária continuasse a ser um debate ideológico, não se constituindo em algo concreto no país. A partir de então, a política agrária ficou diretamente ligada à Presidência da República com a criação, em 1996, do Ministério Extraordinário de Política Fundiária e, em 2000, com o Decreto no 3.338, que originou o Ministério do Desenvolvimento Agrário (INCRA, 2019)5 .

Todavia, de acordo com Medeiros (2003), apesar da definição explícita da função social da terra, a Constituição Federal de 1988 contém uma série de mecanismos que visam bloquear o desenvolvimento de uma reforma agrária tal como defendida pelos trabalhadores do campo. Um exemplo disso é a definição de que as desapropriações deveriam ser feitas sempre através de prévia e justa indenização em Títulos da Dívida Agrária (TDA), preservando o valor real da terra e resgatáveis em no máximo 20 anos. Consolidou-se, assim, a tendência de que a desapropriação fosse realizada com base nos valores do mercado, eliminando o caráter punitivo das desapropriações, pretendido historicamente pelos movimentos sociais.

O Brasil seguiu os modelos de desenvolvimento adotados por muitos países em desenvolvimento, especialmente nos períodos mais contemporâneos, que tendem a concentrar seus poucos recursos no processo de industrialização urbana, acelerando, por conseguinte, o êxodo rural. Contudo, especialistas indicam que a solução mais coerente em termos de promoção do bem-estar social seria tornar o meio rural mais atrativo, com o intuito de manter a população no campo, garantindo-lhes melhor qualidade de vida. Para tanto, conforme Kageyama (2009), uma das alternativas em desenvolvimento local e sustentável é a criação de assentamentos rurais.

Frente ao contexto agrário brasileiro, os assentamentos rurais podem representar para os agricultores familiares assentados novas formas de produzir, novas formas de utilização e controle do tempo de trabalho e, principalmente, a realização de atividades e relações sociais inovadoras (BERGAMASCO, 1997). A diversidade e a heterogeneidade da agricultura familiar brasileira são facilmente observadas nesses ambientes (MEDEIROS, 2003), de tal sorte que, conforme Zimmermann (1994, p. 205), “o assentamento é estudado enquanto um espaço de relações sociais onde as características heterogêneas individuais, homogeneizadas no processo de luta pela terra, ressurgem em bases novas”.

5 Extinto em maio de 2016. 
Bergamasco, Pamard e Chonchol (1997) destacam que a luta pela terra promove relativa homogeneidade dos agricultores familiares, que possuem metas em comum e reforçam a identidade simbólica do movimento social. Assim, os autores definem assentamentos rurais como espaços onde são expressos conteúdos históricos, que resultam de processos políticos e sociais, promovem a materialização das relações sociais. Inferem ainda que o assentamento rural objetiva a transformação de determinado espaço físico, contendo um território habitado, cujo trabalho das famílias visa à exploração desse espaço.

Nesse sentido, Leite (2004) observa que no Brasil a definição de assentamento rural sempre esteve relacionada à atuação do Estado, direcionando a delimitação do espaço criado. O autor destaca que o papel de destaque do Estado se dá em virtude da sua função intransferível de regularizar a questão fundiária. Desde 1970, o INCRA (Autarquia Federal) assumiu a missão prioritária de executar a reforma agrária e realizar o ordenamento fundiário nacional, responsável por trabalhar para o fortalecimento da agricultura familiar em 30 superintendências regionais (LEITE, 2007; INCRA, 2019).

Institucionalmente o INCRA (2019) define o assentamento rural como o conjunto de unidades agrícolas independentes entre si, que são instaladas pelo Órgão em um local onde originalmente existia um único imóvel rural. Cada unidade chamada de parcela (gleba ou lote) é entregue pelo INCRA a uma família hipossuficiente, a qual dificilmente conseguiria adquiri-la por outra via. A quantidade de lotes de cada assentamento varia em função do tamanho da área desapropriada, do número de famílias e da capacidade produtiva de cada região do país. A área e a localização de cada lote geralmente são determinadas pela topografia do terreno e pela produtividade da terra que o local oferece.

À medida que os agricultores recebem o lote, comprometem-se a morar na parcela e a explorá-la para sua subsistência, utilizando para isso exclusivamente mão de obra familiar. Uma vez assentados, deveriam ter acesso a créditos específicos, assistência técnica, infraestrutura e outros benefícios de apoio ao desenvolvimento de suas famílias. Apesar do período de carência, cada família tem a obrigação de pagar pela terra que recebeu e pelos créditos contratados. Estão proibidos de vender, doar, arrendar, emprestar ou alugar seu lote a terceiros até que possuam a escritura do bem (INCRA, 2019).

A tabela 1, a seguir, apresenta a dinâmica de distribuição de terra no Brasil sob a perspectiva histórica de avaliação dos projetos de assentamentos de reforma agrária. Nela é possível verificar que até 2016 foram assentadas 1.346.798 famílias em todo o país. Todavia, a situação em 31 de dezembro de 2017 era de 972.289 famílias vivendo efetivamente em assentamentos e áreas reformadas (INCRA, 2019). O período com maior número de famílias assentadas no Brasil ocorreu entre 2003-2010, em que 614.088 famílias foram assentadas. O período com maior número de projetos de assentamentos ocorreu entre 1995-2002, com 4.281 PA criados.

Tabela 1 - Número de famílias assentadas e projetos de assentamento criados no Brasil

\section{Período/Governos}

Até 1994

Fernando Henrique Cardoso (1995-2002)

Luiz Inácio Lula da Silva (2003-2010)

Dilma Rousseff (2011 até maio 2016)

Número total de famílias assentadas

Fonte: Guerrero, Bergamasco e Esquerdo (2016, p. 374).
№ de Famílias Assentadas

58.317

540.704

614.088

133.689

1.346 .798

O número elevado de projeto de assentamentos criados entre 1995 e 2002, durante a gestão do presidente Fernando Henrique Cardoso, deve-se basicamente aos conflitos e mortes no campo observados na década de 1990, ocasionados pela forte pressão e mobilização dos movimentos sociais ligados à luta pela terra e à redução considerável de recursos para o crédito agrícola, incentivando boa parte dos proprietários de terras - muitos inclusive endividados - a comercializar suas terras com o INCRA (DEFANTE et al., 1999; MEDEIROS, 2003). Mattei (2012) destaca que, embora os dados da década de 1990 mostrem o grande número de famílias sendo assentadas em todo país, a concentração de terras no mesmo período continuou de forma acentuada, dando prosseguimento ao problema agrário brasileiro.

Entre os anos de 2003 e 2010 houve a ampliação do número de famílias assentadas no Brasil, reflexo das duas gestões do presidente Luís Inácio Lula da Silva, que tinha as reivindicações dos movimentos sociais (urbano e rural) como parte integrante de sua plataforma de governo (GUERRERO; BERGAMASCO; ESQUERDO, 2016). Dessa forma, em 2003 o Governo Federal apresentou o II Plano Nacional de Reforma Agrária, cujas metas visavam assentar 400 mil famílias através de desapropriações, 150 mil famílias através de crédito fundiário, regularizar a posse de 
terras de 500 mil famílias, entre outras (FERNANDES, 2007).

Apesar do assentamento de mais de 381 mil famílias entre 2003 e 2006, o cenário no campo estava longe do ideal, pois conforme Fernandes (2007), o INCRA realizou um “processo autofágico”, prática muito comum desde o governo de Fernando Henrique Cardoso, quando houve superfaturamento dos números de assentamentos criados, fornecendo às famílias terras de assentamentos já existentes ou em áreas públicas, retirando muitas famílias anteriormente assentadas. Segundo informações do INCRA (2006), o ano de 2006 representa um marco no processo dos assentamentos, com mais de 138 mil famílias assentadas. Já no segundo mandato do presidente Luís Inácio Lula da Silva, evidencia-se uma queda gradativa nesse número, com 232 mil famílias assentadas entre 2007 e 2010 . O quadro se agravou a partir de 2011, no mandato da Presidenta Dilma Rousseff, no qual o INCRA assentou até 2016, em média 25 mil famílias por ano.

Os dados referentes ao número total de famílias assentadas podem ser considerados aquém do desejado, segundo Guerrero, Bergamasco e Esquerdo (2016). Os autores indicam que até 2008 existiam no Brasil aproximadamente quatro milhões de agricultores sem-terra e que apenas 1,6\% dos proprietários controlavam até $78 \%$ das terras brasileiras. Destaca-se ainda que, no ano de 2017, foram criados apenas 12 assentamentos em todo Brasil, com nenhuma família assentada (INCRA, 2019). Entretanto, o ritmo de desaceleração na implantação de assentamentos nem sempre ocorreu dessa forma.

\section{Formação econômica no Rio Grande do Sul e o processo de implantação de assentamentos rurais em Santana do Livramento}

Considerado o berço do MST, assim como os demais estados da região sul do país, o Estado do Rio Grande do Sul foi palco de inúmeras mobilizações e reivindicações de agricultores familiares a partir da década de 1970. Essas mobilizações foram motivadas basicamente pelo processo de modernização da agricultura e pela demarcação de áreas indígenas, entre outros. Os primeiros conflitos de luta pela terra começaram em regiões no norte e noroeste do Estado, onde o processo de modernização da agricultura iniciou (CHELOTTI, 2003).

Cabe destacar que o Estado do Rio Grande do Sul teve uma colonização tardia quando comparado a outras regiões do Brasil e das Américas, pois inicialmente não foram observadas riquezas comerciais que interessassem ao mercado europeu (ALBORNOZ, 2000; HEYDT; HOFF; TROIAN, 2018). Conforme Chelotti (2009), a diversidade na colonização do Rio Grande do Sul, marcada historicamente pela presença dos espanhóis jesuítas (1620), portugueses (1700), alemães (1824) e italianos (1875) possibilitou uma importante dinâmica territorial no Estado.

Nesse sentido, Heydt, Hoff e Troian (2018) observam que o processo histórico de formação econômica do Rio Grande do Sul está fortemente ligado à atividade agropecuária, tendo em vista que, mesmo antes da presença luso-brasileira em solo gaúcho, a pecuária de animais vacuns e muares era encontrada em abundância nas civilizações espanholas jesuítas. Conforme Furtado (2007), a pecuária do sul do Brasil passou a ser valorizada apenas no século XVIII, com o propósito de ser meio de transporte para a atividade mineradora presente no sudeste e, com isso, possibilitou a integração do Estado com a economia brasileira.

Enquanto a presença espanhola e luso-brasileira no Estado destinava-se à atividade pecuária nas regiões de planícies e campanha, com a predominância econômica dos latifúndios e a pecuária de baixa lotação, as zonas de matas - até então desprestigiadas - foram destinadas aos colonos alemães e italianos a partir do século XIX (CHELOTTI, 2009; ROCHA et al., 2017). Diferentemente da colonização espanhola e luso-brasileira, esses imigrantes se dedicaram à agricultura diversificada em pequenas propriedades rurais e deram início ao processo de desenvolvimento do norte do Estado. "Estavam lançados os pilares da propriedade camponesa nas áreas florestais do Rio Grande do Sul” (CHELOTTI, 2009, p 75).

De acordo com Pebayle (1975), até o começo do século XX, os contatos entre os produtores rurais luso-brasileiros e os policultores italianos e alemães foram raros, pois havia uma tendência de afastamento dessas duas sociedades rurais postas por suas origens étnicas, tradições culturais e suas mentalidades distintas.

A aristocracia local foi sempre constituída pelos “estancieiros”. Esses homens rudes e fatigados das violentas técnicas da pecuária de uma outra época, afeitos a deslocamentos e já curiosos a respeito das novidades técnicas de seus vizinhos do Prata, rejeitaram maciçamente o arado, a inovação agrícola e as terras de floresta. O colono era a antítese desses gaúchos das campinas: era o homem da floresta, o agricultor isolado com técnicas ainda predatórias, o pequeno proprietário. O campo não o atraía. E, quando os lotes originais estavam se tornando muito reduzidos para lhes permitir viver, era para outras florestas que eles emigravam (PEBAYLE, 1975, p. 1).

As áreas florestais e de serra, sempre indesejadas pelos pecuaristas, tornaram-se territórios de reprodução social, fundamentais para os imigrantes italianos e alemães em solo gaúcho, fazendo com estes desenvolvessem diversas 
colônias pautadas na agricultura familiar diversificada e na pequena propriedade. Com o passar do tempo, o crescimento populacional observado, aliado ao processo de modernização da agricultura, desempregou grande parte desses trabalhadores. Desta forma, parte dos agricultores familiares descendentes de italianos e alemães iniciaram a constituição dos movimentos sociais reivindicatórios no meio rural do Rio Grande do Sul (MEDEIROS, 2001; CHELOTTI, 2009). A denominação "colono", que também representa a figura do agricultor familiar assentado, teve origem nessa descendência italiana e alemã de grande parte desses agricultores (MEDEIROS, 2001; MONTEBLANCO, 2013).

Conforme Navarro et al., (1999, p. 27), é nesse contexto de desigualdade econômica e social, de aumento da concentração fundiária e de renda, que emergem os primeiros movimentos reivindicatórios no meio rural gaúcho, entre eles o MST, "principal força propulsora dos processos sócio-políticos que resultaram na constituição dos assentamentos rurais e seus impactos". Para Schneider e Silveira (1991), a implantação dos primeiros assentamentos em solo gaúcho ocorreu a partir de 1978 e teve como idealizadores as esferas de Governo Estadual, em maior medida, e Federal. Conforme os autores, entre os anos de 1978 e 1990, o Governo Estadual implantou 47 assentamentos no Estado, que juntos receberam aproximadamente 1.500 famílias. Ademais, o Fundo de Terras do Estado do Rio Grande do Sul (FUNTERRA-RS) foi a forma encontrada para a concretização dos primeiros assentamentos no Estado. Os agricultores eram oriundos das regiões serra, noroeste, planalto, depressão central e em menor medida da Campanha (Bagé).

Nesse mesmo período, mais especificamente entre os anos de 1986 e 1990, o INCRA implantou os primeiros assentamentos ligados ao Governo Federal no Estado gaúcho. A criação de 17 assentamentos - sendo que destes 15 foram oriundos de desapropriação e dois oriundos de terras do governo federal - possibilitou que aproximadamente 1.000 famílias fossem assentadas inicialmente. Ademais, as terras destinadas aos primeiros assentamentos gaúchos foram oriundas de compras, desapropriações e duas áreas pertencentes ao poder público (SCHNEIDER; SILVEIRA, 1991). Os autores observam que até 1990 não houve uma política de reforma agrária no Estado e os assentamentos eram implementados pelas próprias famílias, que pressionaram o poder público, através de diversos acampamentos, fazendo com que Governo Estadual disponibilizasse terras aos colonos através do FUNTERRA-RS.

Conforme Navarro et al., (1999), outro fator determinante para a luta em prol da implantação de assentamentos no Estado foi a necessidade de se obter colocação para a população rural excedente da região norte do Rio Grande do Sul, vitimada pelo processo de êxodo rural em virtude do esgotamento da fronteira agrícola no Estado e pela subordinação dos agricultores familiares ao capital agroindustrial.

Dessa forma, Rocha et al., (2017) destacam a importância da metade sul do Estado, marcada historicamente pela presença de terras em abundância, no desenvolvimento dos assentamentos que receberam, a partir de 1990, os colonos do norte do Estado. Um dos municípios da metade sul que reconhecidamente recebeu um grande número de assentamentos foi o município de Santana do Livramento.

O município de Santana do Livramento tornou-se referência para o estudo da agricultura familiar assentada devido a dois motivos, a saber: i) é o município gaúcho com maior número de assentamentos rurais; ii) apresenta o contraste entre a agricultura familiar assentada e a histórica presença das grandes propriedades rurais, voltadas para o agronegócio (CHELOTTI, 2003; AGUIAR, 2011; MONTEBLANCO, 2013; TROIAN, BREITENBACH, 2018).

Sendo assim, a pressão dos movimentos sociais no campo, aliada à necessidade de alocação da população rural excedente da região norte do Rio Grande do Sul, colocou Santana do Livramento no mapa dos assentamentos, implementando 30 assentamentos desde 1992. Os primeiros assentamentos criados no município eram compostos, quase que exclusivamente, por colonos vindos do norte do Estado (CHELOTTI, 2003; AGUIAR, 2011). A tabela 2, a seguir, apresenta comparativo entre o número de assentamentos rurais existentes no Brasil, no Rio Grande do Sul e em Santana do Livramento, destacando a área de abrangência e o total de famílias amparadas.

Tabela 2 - Assentamentos rurais no Brasil, Rio Grande do Sul e Santana do Livramento (RS)

\begin{tabular}{|c|c|c|c|c|}
\hline & $\begin{array}{c}\text { Número } \\
\text { de famílias } \\
\text { assentadas }\end{array}$ & $\begin{array}{l}\text { Capacidade total de } \\
\text { famílias assentadas }\end{array}$ & $\begin{array}{c}\text { Número de } \\
\text { assentamentos }\end{array}$ & $\begin{array}{c}\text { Área de } \\
\text { assentamentos } \\
\text { (ha) }\end{array}$ \\
\hline Brasil & 972.289 & 1.179 .058 & 9.374 & $87.978 .041,18$ \\
\hline Rio Grande do Sul & 12.413 & 13.821 & 345 & $294.194,28$ \\
\hline Santana do Livramento & 907 & 1.000 & 30 & $26.258,14$ \\
\hline
\end{tabular}


Verifica-se que aproximadamente um milhão de famílias assentadas no Brasil, mais de 12 mil famílias no Rio Grande do Sul e 907 famílias assentadas em Santana do Livramento. Dos 694.161 hectares do município de Santana do Livramento, apenas $3,78 \%$, (ou $26.258,14$ hectares) foram destinados à reforma agrária.

De acordo com Chelotti (2003), a história dos assentamentos rurais em Santana do Livramento teve início a partir das primeiras vistorias realizadas pelo INCRA nas propriedades rurais da Campanha Gaúcha, fatos ocorridos em meados de 1990. Conforme o autor, as vistorias foram organizadas em virtude dos baixos índices de lotação pecuária por hectare. As intervenções do INCRA, ao longo da década de 1990, resultaram em uma série de desapropriações $\mathrm{e}$, posteriormente, na criação de assentamentos rurais.

Monteblanco (2013) salienta que os primeiros assentamentos instalados em Santana do Livramento, entre $1992 \mathrm{e}$ 2002, não foram precedidos por ocupações ou conflitos fundiários ocorridos no próprio município, diferenciando-se dos outros municípios da Campanha Gaúcha, região norte e noroeste do Estado, onde os conflitos pelo direito de acesso à terra foram marcantes. O autor reforça que, em um primeiro momento, não houve resistência por parte dos fazendeiros santanenses em acolher as famílias assentadas, mas sim, certo interesse na comercialização das terras, devido às sucessivas crises da pecuária.

O fato é que Santana do Livramento, em linhas gerais, apresentou condições favoráveis à instalação de assentamentos, se comparado com outros da Campanha Gaúcha. Pois, além de dispor de terras adequadas ao desenvolvimento da agricultura familiar, sobretudo em sua parte leste, não apresentou grande resistência por parte dos fazendeiros, ao menos nesta primeira década (1992 - 2002). Inclusive, muitos proprietários se interessaram em negociar suas terras para fins de reforma agrária ou mesmo em ter suas terras vistoriadas pelo INCRA para fins de desapropriação, já que esta prevê indenização. Este interesse partiu principalmente daqueles proprietários descapitalizados, que foram diretamente afetados pelas sucessivas crises da pecuária (MONTEBLANCO, 2013, p. 190).

A ausência de conflitos no meio rural de Santana do Livramento pode ser explicada pela situação econômica do país na década de 1990. De acordo com Gimenes, Gimenes e Gozer (2008), a década foi marcada pela abertura comercial, pelo processo de estabilização dos preços e pela gradual saída do governo no financiamento da agricultura visando o controle dos gastos públicos, diminuindo drasticamente os recursos destinados ao Sistema Nacional de Crédito Rural (SNCR). Conforme Monteblanco (2013), essas medidas geraram desinteresse de alguns produtores pela terra, o que possibilitou a compra, com preços maiores que os preços de mercado, pelo INCRA.

Chelotti (2003) destaca que até 2002 foram criados 21 assentamentos rurais no município. Conforme o autor, 17 foram organizados pelo MST; dois pelo Projeto Minha Terra organizados em cooperativas de produção agrícola, tendo como caráter estadual; um pelo Programa Banco da Terra, com recursos federais destinados a trabalhadores rurais do município de Santana do Livramento e um assentamento oriundo do reassentamento de colonos posseiros de terras indígenas.

A implantação de assentamentos no município aumentou significativamente as demandas do MST por infraestrutura e políticas públicas, o que desencadeou diversos atritos entre a Prefeitura Municipal e o MST, principalmente durante a gestão municipal de 1997 a 2000. A partir de 2003, após o desenvolvimento de 22 assentamentos no município, a tensão entre fazendeiros e agricultores do MST se acirrou (MONTEBLANCO, 2013). Um grupo de agricultores dos municípios de Candiota, Hulha Negra, Bagé, Dom Pedrito, Santana do Livramento, Cacequi, São Gabriel e Rosário do Sul alocou-se no Passo da Faxina, localidade a aproximadamente $35 \mathrm{~km}$ do centro urbano de Santana do Livramento para montar o novo acampamento. Outro grupo composto por aproximadamente cinquenta fazendeiros locais construiu um acampamento, a cerca de 1,5 quilômetros do acampamento do MST, com o intuito de monitorar e evitar possíveis futuras invasões.

Outras situações de ocupação de terra e prédios públicos também foram organizadas pelo MST no período. A situação de conflitos observados no campo, a partir dos anos 2000, pode ser explicada pela retomada de aporte de recursos no SNCR, o que valoriza a terra e a produção agropecuária. Entretanto, mais oito assentamentos foram criados no município até o ano de 2008, fazendo com que Santana do Livramento se consolidasse como importante núcleo de reforma agrária no Rio Grande do Sul (AGUIAR, 2011; MONTEBLANCO, 2013).

Atualmente, dois dos dezessete vereadores eleitos no município da gestão 2017/2020, possuem como seus principais colégios eleitorais as áreas de assentamento, inclusive um deles é assentado. A organização política dos assentados faz com que, por diversas vezes sejam observadas manifestações e reuniões no interior da Prefeitura Municipal, oportunidade em que os agricultores apresentam suas demandas e cobram do executivo ações para a resolução de problemas de infraestrutura, transporte escolar, manutenção de estradas e pontes, entre outras reinvindicações.

Cabe mencionar que a instalação dos assentamentos rurais no município inseriu novos atores sociais na "cidade símbolo do Mercosul". Neste sentido, a tabela 3 demonstra as especificidades dos 30 assentamentos desenvolvidos no município, bem como a capacidade e o número de famílias assentadas, a área e a data de criação. 
Tabela 3 - Assentamentos implantados em Santana do Livramento/RS (PA e PE) ${ }^{6}$

\begin{tabular}{|c|c|c|c|c|}
\hline Assentamento & $\begin{array}{c}\text { Capacidade em } \\
\text { famílias }\end{array}$ & Famílias Assentadas & $\begin{array}{c}\text { Área PA } \\
\text { (hectares) }\end{array}$ & Data criação \\
\hline PA Cerro do Munhoz & 67 & 61 & 1577 & $10 / 06 / 1992$ \\
\hline PA São Joaquim & 37 & 37 & 1040,10 & 11/11/1996 \\
\hline PA Apolo & 35 & 34 & 950,05 & $11 / 11 / 1996$ \\
\hline PA Santo Angelo & 17 & 15 & 481,41 & 21/11/1996 \\
\hline PA Bom Será & 26 & 24 & 747,87 & 05/12/1996 \\
\hline PA Coqueiro & 35 & 31 & 980,10 & $10 / 12 / 1996$ \\
\hline PA Jupira/São Leopoldo & 45 & 43 & 1264 & 04/06/1997 \\
\hline PA Recanto & 23 & 23 & 665 & $29 / 08 / 1997$ \\
\hline PA Posto Novo & 21 & 21 & 665,28 & $14 / 10 / 1997$ \\
\hline PA Santa Rita II & 22 & 20 & 697 & $14 / 10 / 1997$ \\
\hline PA Frutinhas & 20 & 19 & 565,28 & 15/10/1997 \\
\hline PA Capivara & 26 & 23 & 693,85 & $23 / 11 / 1998$ \\
\hline PA Pampeiro & 50 & 44 & 1338,81 & $17 / 12 / 1998$ \\
\hline PE União Rodeiense & 24 & 17 & 387 & 02/12/1999 \\
\hline PE Nova Esperança & 43 & 43 & 1216 & $13 / 12 / 1999$ \\
\hline PE Esperança da Fronteira & 22 & 21 & 422 & $09 / 10 / 2000$ \\
\hline PE Nova Madureira & 24 & 24 & 596,81 & $10 / 12 / 2001$ \\
\hline PE Rincão da Querência & 8 & 3 & 202,11 & $20 / 02 / 2002$ \\
\hline PE Torrão & 22 & 19 & 505,54 & $13 / 03 / 2002$ \\
\hline PE Paraíso II & 7 & 7 & 136 & $05 / 12 / 2002$ \\
\hline PE Roseli Nunes & 63 & 56 & 1742,37 & $05 / 12 / 2002$ \\
\hline PE Conquista do Cerro da Liberdade & 85 & 68 & 2475,56 & $12 / 12 / 2002$ \\
\hline PA Fidel Castro & 58 & 58 & 1499,87 & $08 / 08 / 2005$ \\
\hline PA Leonel Brizola & 13 & 13 & 353,34 & $08 / 08 / 2005$ \\
\hline PA Sepé Tiarajú III & 43 & 41 & 1340,71 & $06 / 04 / 2006$ \\
\hline PA 31 de Março & 12 & 11 & 301,85 & $06 / 04 / 2006$ \\
\hline PA São João II & 33 & 26 & 782,84 & $26 / 07 / 2006$ \\
\hline PA Herdeiros de Oziel & 43 & 35 & 997,28 & $02 / 04 / 2007$ \\
\hline PA Banhado Grande II & 11 & 11 & 258,38 & $02 / 04 / 2007$ \\
\hline PA Ibicuí & 65 & 59 & 1374,63 & $20 / 06 / 2008$ \\
\hline TOTAL & 1.000 & 907 & $26.258,14$ & - \\
\hline
\end{tabular}

Fonte: Elaboração própria com base em INCRA (2019). Situação em 31/12/2017.

6 Assentamentos tidos como PA (Projeto de Assentamento Federal) correspondem a modalidades de projetos criados pelo INCRA, enquanto que assentamentos tidos como PE (Projeto de Assentamento Estadual) correspondem a Projetos reconhecidos pelo INCRA, porém tiveram sua origem vinculada ao Governo Estadual. 
A tabela 3 indica que durante a década de 1990 foram criados 13 PA's no município. Grande parte deu-se durante a gestão do presidente Fernando Henrique. Também é possível verificar que os nove PE’s presentes no município foram implantados entre os anos de 1999 e 2002. Nesse sentido, Chelotti (2003) destaca que até o fim do ano de 2002, Santana do Livramento já era o maior polo de assentamentos rurais do Estado do Rio Grande do Sul, resultado de uma política de criação de assentamentos rurais via Governo Estadual, durante a gestão do Governador Olívio Dutra (1999-2002). Nos anos 2000, mais oito PA’s foram criados no município tendo como última implantação o PA Ibicuí em 2008.

De acordo com Aguiar (2011), os assentamentos rurais de Santana do Livramento são extremamente complexos, pois agregam a experiência do acampamento anterior e as relações sociais estabelecidas naquele espaço com a experiência cultural de cada família, considerando a origem geográfica diversa dos assentados. Vale destacar também que foram assentados no município diversos trabalhadores rurais de antigas fazendas, o que - em alguns casos viabilizou que esses agricultores desempenhassem papel fundamental na instalação dos assentamentos. A autora informa que os assentamentos rurais do município geram inúmeras relações espontâneas, como os processos de auto-organização, oferecendo possibilidades concretas de fornecimento de alimentos para a sociedade.

Aguiar (2011) e Chelotti (2013) citam os aspectos socioculturais da agricultura familiar assentada do município. Conforme Chelotti (2013), o modo de vida campeiro - localizado, principalmente, na Metade Sul do estado - alia-se com o modo de vida dos colonos descendentes de colonização ítalo-germânica - principalmente na metade norte do estado - modificando e incorporando hábitos socioculturais nos dois segmentos, como o jeito de falar, a construção das casas, a organização do trabalho e o laço comunitário. Para Monteblanco (2013), com a diversidade e a riqueza da agricultura familiar assentada, tem-se aumentado a visibilidade destes atores sociais junto à comunidade local.

Por fim, cabe destacar que a instalação dos assentamentos rurais em Santana do Livramento foi um dos principais propulsores do desenvolvimento na região, já que possibilitou que agricultores, outrora desprovidos de terra, vivam e produzam no campo de forma digna. Neste sentido, verifica-se que o conjunto de atividades realizadas pelos assentados tem demandado maior atenção do Estado para com políticas públicas para o meio rural. As atividades realizadas pelos assentados, sejam agrícolas, relacionadas a serviços de educação, ou relativas a pluriatividade, entre outras obrigam o poder público a estar constantemente avaliando, se reorganizando e adotando novas formas de gestão para proporcionar melhores condições de vida à categoria social.

\section{Considerações finais}

A luta pela terra e o estabelecimento dos assentamentos rurais em Santana do Livramento ocorreu em concomitância ao processo de fortalecimentos das políticas em reforma agrária no Brasil. Em especial, a presença da agricultura familiar assentada no município foi parte integrante de um importante movimento ocorrido em todo país, que no Estado do Rio Grande do Sul iniciou na metade norte com a participação de colonos desprovidos de terra e descendentes de alemães e italianos.

A partir da década de 1990, com a criação de 15 assentamentos entre PA's e PE's, o município começou a fazer parte do mapa da reforma agrária brasileira, sem expressiva resistência por parte dos fazendeiros locais. A baixa lucratividade das atividades agropecuárias, verificada no início da década de 1990, aliada à redução drástica dos montantes destinados ao crédito rural e ao endividamento dos grandes proprietários foram fatores que possibilitaram, em 1992, a instalação do primeiro assentamento rural em Santana do Livramento.

Contudo, esse quadro modificou-se no início dos anos 2000, período em que houve o desenvolvimento de mais 15 assentamentos de reforma agrária. A discordância com a vinda dos agricultores assentados resultou em diversos episódios de conflitos públicos, protagonizados por pecuaristas tradicionais do município, entes públicos e demais atores sociais. Os períodos de tensão política das décadas passadas contrastam com a organização política e reivindicatória atual do segmento, que tem na diversidade sociocultural uma de suas maiores riquezas.

Os assentamentos rurais no município deram uma nova dinâmica ao sistema produtivo e a cultura local. As mais de 900 famílias assentadas alteraram e intensificaram as relações sociais, culturais e produtivas existentes, dando mais "movimento" à Santana do Livramento e a metade sul do Estado como um todo. Através da produção, seja para a subsistência ou para a comercialização, os assentados dão vida ao campo, comercializam em cadeias curtas (feiras, mercados institucionais, entre outros), demandam a manutenção das estradas rurais, a organização do transporte escolar, realizam festas, jogos, frequentam a universidade (pública, como a Universidade Federal do Pampa e estadual, como a Universidade Estadual do Rio Grande do Sul), enfim, dinamizam a economia e a cultura local. 


\section{Referências}

ALBORNOZ, V. P. L. Fronteira Gaúcha: Santana do Livramento. Caderno de História: Memorial do Rio Grande do Sul. Secretaria de Estado da Cultura - Governo do Estado do Rio Grande do Sul. Porto Alegre, 2000.

AGUIAR, J. S. Uso da terra, técnica e territorialidade: os assentamentos de Santana do Livramento, RS. Dissertação (Mestrado em Geografia). Universidade Federal do Rio Grande do Sul, Porto Alegre, 2011.

BACHA, C. J. Economia e política agrícola no Brasil. 2ª ed. São Paulo: Atlas, 2012.

BERGAMASCO, S. M. P. P. A realidade dos assentamentos rurais por detrás dos números. Estudos Avançados, São Paulo, v. 11, n. 31, p.37-49, set./dez.1997.

BERGAMASCO, S. M. P. P.; PAMARD, C. B.; CHONCHOL, M. E. Por um Atlas dos Assentamentos brasileiros: espaços de pesquisa. Rio de Janeiro: DL Brasil, 1997.

CAGGIANI, I. Sant'Ana do Livramento: 150 anos de história. I Volume. Sant'Ana do Livramento, ASPES, 1983.

CHELOTTI, M. C. A instalação de assentamentos rurais e a inserção de novos agentes no espaço agrário do município de Sant'Ana do Livramento - RS. 2003. Dissertação (Mestrado em Geografia), Universidade Estadual Paulista, São Paulo, 2003.

CHElotTi, M. C. A Estância Metamofoseou-se:(re) configurações territoriais e expressões da reterritorialização camponesa na Campanha Gaúcha. (1990-2007). 2009. Tese (Doutorado em Geografia). Universidade Federal de Uberlândia, Uberlândia, 2009.

DELGADO, G. C. Expansão e modernização do setor agropecuário no pós-guerra: um estudo da reflexão agrária. Estudos Avançados, São Paulo, v.15, n.43, p.157-172, 2001.

DELGADO, G. C. A questão agrária no Brasil, 1950-2003. In: JACCOUD, L. Questão social e políticas sociais no Brasil contemporâneo. Brasília: Ipea, 2005. p. 51-90.

DEFANTE, M et al. O papel do crédito agrícola brasileiro e sua distribuição por estratos de produtores. Teoria e Evidência Econômica, Passo Fundo, v. 7 n. 12, p. 87-110, 1999.

FERNANDES, B. M. Formação e territorialização do MST no Brasil: 1979-2005. In: MARAFON, G. J; RUA, J., RIBEIRO, M. A. (orgs). Abordagens teórico-metodológicas em geografia agrária. Rio de Janeiro: UERJ. 2007. p.139-168.

FERron, J. L., TROIAN, A., ALBUQUERQUE, C. T. A agricultura familiar assentada: da luta pela terra ao seu estabelecimento em Santana do Livramento/RS. In: Anais...8 Fórum Internacional - ECOINOVAR, Universidade Federal de Santa Maria, Santa Maria, de 15 a 17 de outubro de 2019.

FILIPPI, E. E. Reforma Agrária: experiências internacionais de reordenamento agrário e a evolução da questão da terra no Brasil. Porto Alegre: Editora UFRGS, 2005.

FREITAS, L. M; MAIA, F. J. F; FILHO, E. F. S. A ocupação territorial brasileira como imperativo da expansão do capital comercial português e como conseqüência das contradições intermercantilistas: O caso do regime sesmarial brasileiro e a função do direito na sociedade do Brasil-colônia. In: Anais.... 6 Colóquio Internacional Marx e Engels, Unicamp, Campinas, SP, 2009.

FURTADO, C. A economia latino-americana: formação histórica, e problemas contemporâneos. 4.ed. São Paulo: Companhia das Letras, 2007.

GIMENES, R. M. T., GIMENES, F. P., GOZER, I. C. Evolução do crédito rural no Brasil e o papel das cooperativas agropecuárias no financiamento dos produtores rurais. In: Anais... 46 Congresso da Sociedade Brasileira de Economia, Administração e Sociologia Rural, Rio Branco, 2008. 
GRAZIANO DA SILVA, J. A modernização dolorosa: estrutura agrária, fronteira agrícola e trabalhadores rurais no Brasil. Rio de Janeiro: Zahar, 1981.

GUERRERO, I. C. O., BERGAMASCO, S. M. P. P., ESQUERDO, V. F. S. Reforma Agrária: contribuições para o debate. Retratos de Assentamentos, v. 19, n. 1, p. 351-380, 2016.

HEYDT, D., HOFF, D. N., TROIAN, A. A Formação Econômica de Santana do Livramento/RS: Análise da Pecuária como Eixo Estrutural. Revista Estratégia e Desenvolvimento, Santana do Livramento, v. 2, n. 1, p.3254, jul. 2018.

INCRA - INSTITUTO NACIONAL DE COLONIZAÇÃO E REFORMA AGRÁRIA. 2017. Disponível em: <https:// www.incra.gov.br>. Acesso em 07 dez. 2017.

INCR - INSTITUTO NACIONAL DE COLONIZAÇÃO E REFORMA AGRÁRIA. Informações gerais sobre os assentamentos da Reforma Agrária. Disponível em: <http://painel.incra.gov.br/sistemas/index.php>. Acesso em: 01 fev. 2019.

KAGEYAMA, A. Desenvolvimento rural no Rio Grande do Sul. In: SCHNEIDER, S. A diversidade da Agricultura Familiar. Porto Alegre: UFRGS Editora, 2009.

LEITE, S. P. Autoconsumo y sustentabilidad en la agricultura familiar: una aproximación a la experiencia brasileña. In: BELIK, W. (org.), Políticas de seguridad alimentaria y nutrición en América Latina, São Paulo: Hucitec, 2004.

MARTINS, J. S. Os camponeses e a política no Brasil: as lutas sociais no campo e seu lugar no processo político. Petrópolis: Vozes, 1995.

MATTEI, L. F. Pluriatividade e desenvolvimento rural no estado de Santa Catarina. 1999. Tese (Doutorado em Economia), Universidade Estadual de Campinas, Campinas, SP, 1999.

MEDEIROS, L. S. Reforma agrária no Brasil: história e atualidade da luta pela terra. São Paulo: Fundação Perseu Abramo, 2003.

MIRANDA, E. L., FIUZA, A. L. C. Movimentos Sociais Rurais no Brasil: o estado da arte. Rev. Econ. Sociol. Rural, Brasília, v. 55, n. 1, p. 123-136, 2017.

MOCELIN, D. G. Movimentos sociais e movimentos sociais rurais. In: GEHLEN, I.; MOCELIN, D. G. Organização social e movimentos sociais rurais. Porto Alegre: Editora da UFRGS, 2018.

MONTE, F. C. D. O INCRA e a política de Assentamentos Rurais: um estudo sobre processos político-administrativos de ação pública. 2013. Tese (Doutorado em Ciências Sociais em Desenvolvimento, Agricultura e Sociedade), Universidade Federal do Rio de Janeiro, Rio de Janeiro, 2013.

MONTEBLANCO, F. L. O Espaço rural em questão: formação e dinâmica da grande propriedade e dos assentamentos da reforma agrária em Santana do Livramento/RS. 2013. Dissertação (Mestrado em Geografia), Universidade Federal do Rio Grande do Sul, Porto Alegre, 2013.

NAKATANI, P., FALEIROS, R. N., VARGAS, N. C. Histórico e os limites da reforma agrária na contemporaneidade brasileira. Serviço Social e Sociedade, São Paulo, n.110, p. 213-240, 2012.

NAVARRO, Z. et al. Pequena história dos assentamentos rurais no Rio Grande do Sul: formação e desenvolvimento. p.1968. In: MEDEIROS, L. S.; LEITE, S. (Orgs.). A formação dos assentamentos rurais no Brasil. Porto Alegre: EDUFRGS, 1999.

OLIVEIRA, A. A. Critérios de Avaliação de Qualidade e a Consolidação de assentamentos de Reforma agrária no Brasil: a experiência do "Programa de consolidação e emancipação" (auto-suficiência) de assentamentos resultantes de reforma agrária - PAC. 2010. Tese (Doutorado em Desenvolvimento Rural), Universidade Federal 
do Rio Grande do Sul, Porto Alegre, 2010.

PALMEIRA, M. Modernização, Estado e Questão Agrária. Estudos Avançados, São Paulo, v.3, n.7, p. 87-108, 1989.

PEBAYLE, R. Os difíceis encontros de duas sociedades rurais. Boletim Geográfico do RS, Porto Alegre, n.18, p. 1-20, 1975.

PEREIRA, I. A. G. Assentamentos rurais e qualidade de vida: um estudo de caso no PA Santa Verônica Município de Damião/PB. 2013. Dissertação (Mestrado em Desenvolvimento Regional), Universidade Estadual da Paraíba, Campina Grande, 2013.

PiMEnTel, A. E. B. Assentamentos de reforma Agrária na Região do Pontal do Paranapanema e seus impactos econômicos e sociais. 2004. Tese (Doutorado em Engenharia da Produção), Universidade Federal de São Carlos, São Carlos, 2004.

PRADO JUNIOR, C. A Questão Agrária. 4.ed. São Paulo, Brasiliense, 1979.

ROMEIRO, A. R. Reforma Agrária e distribuição de renda. In: STÉDILE, J. P. et al. A questão agrária na década de 90. Porto Alegre: UFRGS, 2004.

ROCHA, N. S. et al. Assentamentos Rurais na metade sul do Rio Grande do Sul e a sua compatibilidade com o bioma pampa: estudo no assentamento São Joaquim. Retrato dos Assentamentos, Araraquara, SP, v. 20, n.1, 2017.

SANTOS, M. R. F. Análise social e econômica dos Assentamentos Rurais no Município de Areia-PB. 2014. Dissertação (Mestrado em Administração e Desenvolvimento Rural), Universidade Federal da Paraíba, Recife, 2014.

SCHNEIDER, S. A diversidade da Agricultura Familiar. Porto Alegre: UfRGS Editora, 2009.

SCHNEIDER, I.; SILVEIRA, F. G. Com ocupações e acampamentos fazem-se assentamentos, mas não reforma agrária. Indicadores Econômicos FEE, Porto Alegre, p. 150 - 166, 01 ago. 1991.

TROIAN, A., BREITENBACH, R. Estratégias e formas de Reprodução Social na Agricultura Familiar da Fronteira Oeste do Rio Grande do Sul. Novos Cadernos Naea, Belém, v. 21, p. 1-15, 2018.

VERAS NETO, F. Q. Os problemas do Estado Contemporâneo e a realidade Brasileira. Rio Grande: FURG, 2013.

ZIMMERMANN, N. de C. Os desafios da organização interna de um assentamento rural. P. 2005-224. In: MEDEIROS, L. S et al. Assentamentos rurais: uma visão interdisciplinar. São Paulo: ED. UNESP, 1994. 